\title{
German authority halts primate work
}

Germany's constitution guarantees its citizens the freedom to conduct research - but local authorities in the northern city of Bremen are forcing a leading neuroscientist to halt his primate experiments. A court will probably now have to decide whether the controversial ruling violates federal law.

Andreas Kreiter at the University of Bremen uses 24 macaques to study cognitive processes in the mammalian brain. Germany's largest animal-protection group, the Animal Welfare Association, has for years campaigned against the experiments, claiming that they are intolerably painful and have no short-term therapeutic use.

Local politicians have become increasingly sympathetic to that view. Last year, in a move criticized by scientists as a grab for votes, Bremen's parliament called on the state government to ban Kreiter's primate research (see Nature 446, 955; 2007). After regional elections in May 2007, the newly formed Social Democrat-Green coalition government agreed not to reapprove his experiments when his current licence expires later this year.

On 15 October, Kreiter was officially informed by the senate of health - the local authority in charge of approving animal experiments - that his licence will not be renewed. Referring to "changed societal values", the authority argued that the experiments were "ethically unjustified" because they address long-term scientific questions rather than help develop specific medical therapies.

Kreiter counters that the authority's reasoning is subjective and will not hold legally. "It is a purely arbitrary ethical assessment that doesn't go into the nature and purpose of my work at all," he says.

The authority's logic is "pretty strange", agrees Reinhard Fischer, who oversees the primate experiments on behalf of Wilfried Müller, the university rector. Fischer notes that the ruling ignores a positive judgement rendered last year by an

"This is a flagrant case of political interference with approval procedures, and with the general freedom to do science." expert commission comprising scientists and representatives of animal-welfare organizations. Bremen's government had asked the commission to evaluate Kreiter's work, and it voted in favour of continuing the experiments - deeming them scientifically important and in full accordance with animal-protection laws.

Matthias Kleiner, the president of Germany's main research-funding agency, the DFG, and many neuroscientists have criticized the

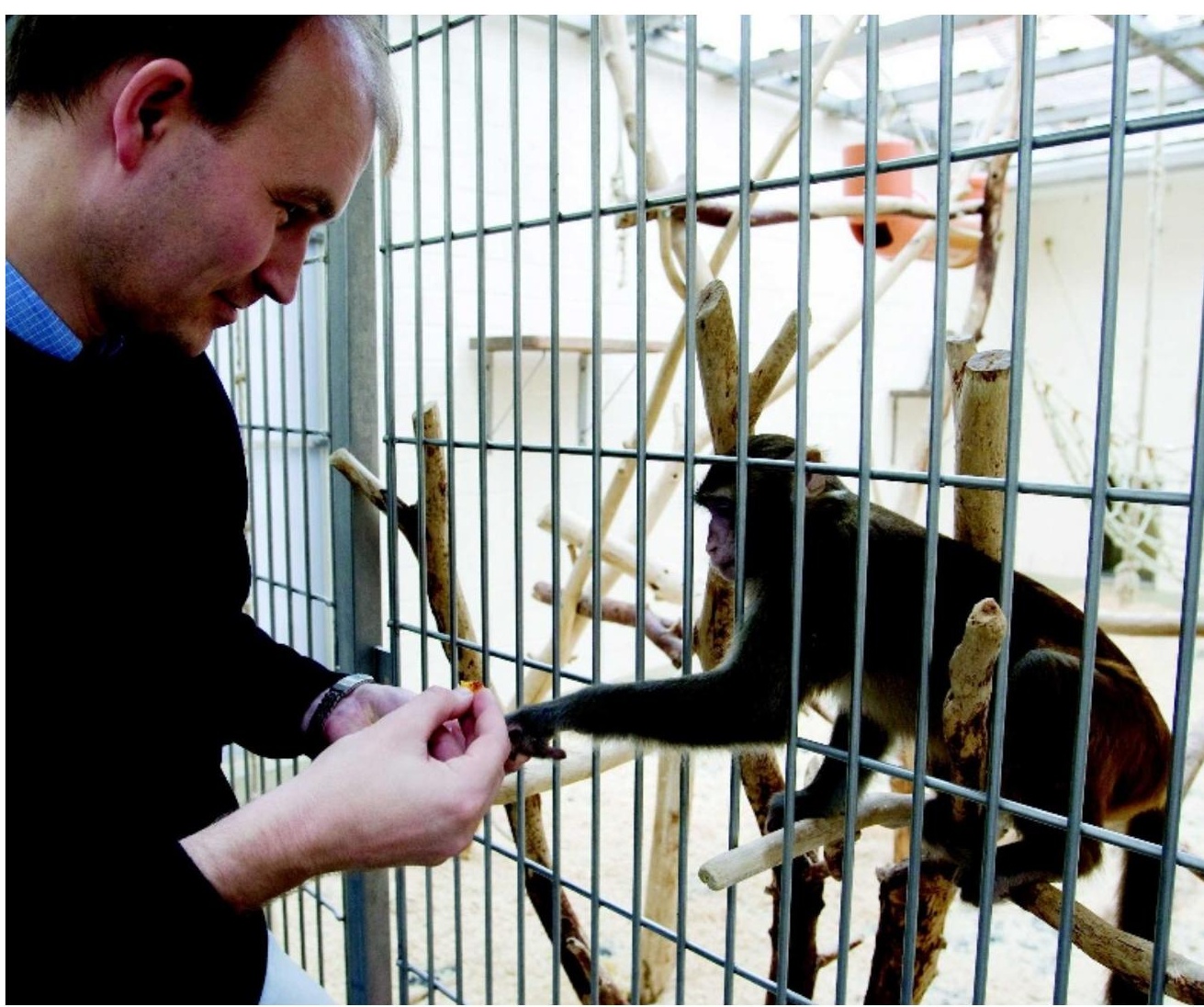

Andreas Kreiter plans to appeal the controversial decision to stop his studies of cognition in macaques.

decision. "We're all very concerned about what's going on in Bremen," says Stefan Treue, director of the German Primate Center in Göttingen and coordinator of EUPRIM-Net, a European Union-funded network of eight large primate centres. "I just can't see why what's perfectly fine in one place should be unethical in another. To me, this is a flagrant case of political interference with approval procedures, and with the general freedom to do science."

Nine laboratories across Germany conduct primate experiments; in recent years the number of animals involved has ranged between 1,300 and 1,800 . About 150 of those are for basic research; the rest are used for other experiments such as drug toxicity tests.

Kreiter's experiments record the activity of single neurons in the brains of macaques while they complete particular behavioural tasks. This cannot be usefully done on animals with less-developed brains, such as mice, or with available non-invasive brain-imaging methods, says Kevan Martin, a neuroscientist at the Swiss Federal Institute of Technology, Zurich, whose own research on macaques is also threatened by a ban (see Nature 453, 833; 2008). "By taking away monkey experiments you certainly greatly diminish the potential benefits of fundamental research like Kreiter's for future clinical applications," says Martin.

The ruling jeopardizes the existence of Kreiter's centre, including the work of a dozen or so postdoctoral researchers and $\mathrm{PhD}$ students. Also at risk is his group's participation in a $€ 2.3$-million (US\$2.9-million) project, funded by the German science ministry and aimed at developing key technologies for neuroprostheses.

Kreiter's current licence to conduct experiments runs out on 30 November. To be able to continue his research beyond that date he will appeal the decision and seek an interim injunction at court.

University officials say they will support him and, if necessary, take the case to Germany's Federal Constitutional Court.

Quirin Schiermeier 